\title{
Nasal Cavity and Ethmoid Sinus Cancer pT4 TNM Finding v8
}

National Cancer Institute

\section{Source}

National Cancer Institute. Nasal Cavity and Ethmoid Sinus Cancer pT 4 TNM Finding v8. NCI Thesaurus. Code C133046.

Nasal cavity and ethmoid sinus cancer with moderately advanced or very advanced local disease. (from AJCC 8th Ed.) 